\title{
Quantifying human vulnerability in rural areas: case study of Tutova Hills (Eastern Romania)
}

\author{
I. C. Stângă and A. Grozavu \\ Department of Geography, Alexandru Ioan Cuza University of Iasi, Carol I 20A, Iasi, Romania
}

Correspondence to: A. Grozavu (adriangrozavu@yahoo.com)

Received: 27 May 2011 - Revised: 31 March 2012 - Accepted: 20 May 2012 - Published: 25 June 2012

\begin{abstract}
This paper aims to assess the vulnerability at regional level, the model and the proposed indicators being explicitly intended for an essentially rural region, in this caseTutova Hills (Eastern Romania). Five categories of variables were taken into account to define the vulnerability components: rural habitat, demographic features, agriculture, environmental quality and emergency situations. For each one, five variables were analyzed and ranked based on the level of determination or subordination. In order to ensure the flexibility of the model and to avoid the criteria duplication in assessing vulnerability, only a single indicator of each category was retained and included in analysis: total number of inhabitants, dependency ratio, weight of arable land on slope categories, weight of land under forestry and road accessibility of villages. The selected indicators were mathematically processed in order to maximize their relevance and to unitary express the results in the spread $0-1$. Also, values of each indicator were grouped into four classes, corresponding to the level of vulnerability: low, medium, high and very high. A general index was obtained through the integration of vulnerability factors in an equation based on the geometric mean. Spatial analysis was based on features of the MicroImages TNTmips 7.3. software, which allow the vulnerability mapping. This approach argues and states that vulnerability assessment through indicator-based methods can be made only according to the level and scale of analysis and related to natural or human conditions of a region.
\end{abstract}

\section{Introduction}

In the last decades, the concept of vulnerability has become increasingly exploited in risk assessment, global change research and environmental and development studies and a conceptual framework has been progressively developed to be applicable for various systems or systemic elements, at multiple scales of analysis and in relation to different hazards (Taubenböck et al., 2008). Generally, vulnerability is defined as the sum of characteristics of an individual or a social group and their situation, characteristics that may affect the ability to anticipate, to cope and to recover from the impact of any hazard (Wisner et al., 2004; Haque and Burton, 2005). Thus, vulnerability assessment requires identifying the susceptibility of elements at risks and determining their relation with any considered hazard (Birkmann, 2006a), but there is still a large variety of points of view, each one being focused either on the exposure, economic context and access to resources or social investigations (UNEP, 2002). To some degree, the great number of definitions and points of view seems to be nearly a normal fact, given the disciplinary context or the existence of many interdisciplinary and transdisciplinary approaches. Whether they refer to applied hazard research (Crozier and Glade, 2005; Fuchs, 2009; Hufschmidt and Glade, 2010; Kuhlicke, 2010; Papathoma-Köhle et al., 2012; Fuchs et al., 2012; etc.), climate and global environmental changes (Liverman, 1990; Kasperson et al., 1990; Dow, 1992; Turner II et al., 2003b; O’Brien et al., 2004; Adger, 2006; Füssel and Klein, 2006; Füssel, 2007; etc.) or development and sustainability context (Chambers, 1989; Watts and Bohle, 1993; Bohle et al., 1994; Cannon, 1994; Turner II et al., 2003a, b; etc.), these definitions have only one common element: the role granted in different ways to receptors in order to explain different impact of hazards (Fuchs et al., 2011).

However, the vulnerability concept and its place in risk assessment evolved in the last decades and two distinct viewpoints (approaches) can be identified: behavioural paradigm and structural paradigm (Mileti et al., 1995; Smith, 2004). 
The behavioural paradigm is hazard-based point of view that emphasizes the role of human adjustment to natural hazards through defensive technical measures, scientific acquirements and emergency plans for disaster mitigation (White, 1974; Hewitt, 1983; etc.). The structural paradigm is rather a cross-hazard and a disaster-based viewpoint that focuses on the vulnerability of socio-economic and political structures to the lack of resources or human exploitation of nature and argues that adaptation to natural hazards is key for reducing risk (Alexander, 1993; Quarantelli, 1998; etc.). Nowadays, the two approaches coexist, but it should be noted that physical scientists have a distinct preference for the behavioural perspective, while the social scientists and human geographers rather prefer the second one (Smith and Petley, 2008).

Other approaches identify three directions in vulnerability research: vulnerability as exposure, vulnerability as social response and place vulnerability (Cutter, 1996). The exposure reflects how a system experiences internal or external perturbations (Adger, 2006), and its analysis should focus on hazardous conditions, human occupancy and level of damages associated with a given event characterized through magnitude, frequency, duration and impact. Social vulnerability should express the ability of society's or individual's capacity to cope with and to recover from a disaster. The third direction, namely the place-based analysis, integrates the exposure and the vulnerability on geographical principles to be applicable at local, regional or global level. Inventories of different definitions of vulnerability with respect to natural hazards research and related debates can be found in Weichselgartner (2001), Fuchs et al. (2007) etc., while a recent criticism of the two aforementioned viewpoints, a conceptual comparative analysis of different vulnerability models and a diagnosis of thought schools are available in Hufschmidt (2011), who put in balance distinct conditions of vulnerability: multiple contexts, multiple dimensions, temporal variability, multiple scales and scale-interdependency.

The conceptual discrepancies due to the different approaches of each science (ecology, human ecology, social sciences, geography and spatial analysis etc.) have influenced the unitary development of rigorous methodology for vulnerability assessment (Schröter et al., 2005). This requires a multidisciplinary approach, an adequate structuring that would allow post hoc comparisons without sacrificing the relevance or the validity, particularly at local level (Polsky et al., 2007). However, the broad and varied conceptualization of vulnerability is also a consequence of its multi-level significance and its multidimensional character: structural, economic, institutional or social vulnerability, all these being interdependent and interacting dimensions (Fuchs, 2009). Reviewing scientific papers shows that the key element in defining and assessing vulnerability can differ from exposure, preparedness and prevention, to coping ability, adaptive capacity and recovering, and each approach identifies the essential peculiarities of human structures (from individual to societal) in their relation with different hazards. Depending on these key elements, some approaches assess quantitatively the financial, material and human losses recorded by a specific element at risk (Varnes, 1984; Meyer and Messner, 2005; Totschnig et al., 2011; Hufschmidt, 2011); other ones evaluate functionally and structurally the insufficient capacity to cope with disaster (Timmerman, 1981; Anderson and Woodrow, 1989; Wisner et al., 2004; Haque and Burton, 2005; Kuhlicke, 2010; Weichselgartner and Bertens, 2000) or combine both of them (Susman et al., 1983; Blaikie et al., 1994; Papathoma-Köhle et al., 2011).

A basic aspect of proper risk assessment is to identify the vulnerability factors, usually divided in two large categories: external factors (exposure to stress/perturbation or to societal structures) and internal factors, which are the basis of coping capacity (Chambers, 1989; Bohle, 2001; Turner II et al., 2003) or biophysical and socio-economic factors (Cutter, 1996; Füssel, 2007). The peculiarities of both categories are very different depending on the geographical or socioeconomical context and on the typology of hazards (Brooks et al., 2005). For this reason, any scientific approach should be a differential analysis, allowing the structural and functional integration of vulnerability (Stângă, 2007), although there are some general factors that can influence the value of vulnerability in any frame and on any level of analysis. Thus, interdisciplinary assessment of vulnerability requires identifying the future needs in the field of vulnerability assessment, such as selection of relevant indicators, transferability of methods, the use of GIS techniques and the existence of output maps (Papathoma-Köhle et al., 2011), integration between natural and/or social approaches, considering scale and hierarchy etc. (Fuchs et al., 2011).

In Romania, except for the socio-medical studies, just a few scientific papers are focused on vulnerability assessment, but the results are rather heterogeneous than conclusive (Armaş et al., 2003, Stângă and Rusu, 2006; Sorocovschi, 2007; Ceobanu and Grozavu, 2009). Therefore, this paper aims at the development of an integrative vulnerability assessment, using a multicriteria analysis and risk assessment method to be applied at regional level for quantifying the general vulnerability of rural communities in Tutova Hills (Eastern Romania), by identifying and integrating specific indicators, which are compatible with the level of analysis and are suitable for mapping. Moreover, the major objective of this approach is to create the vulnerability maps, which would enable local or governmental authorities to conduct their effort towards the most vulnerable regions or towards the critical link from the structural and functional point of view.

\section{Research area}

Tutova Hills $\left(3421 \mathrm{~km}^{2}\right)$ are a distinct geographical unit in the eastern part of Romania (Fig. 1) clearly bounded westward and eastward by two large valleys (those of Siret and 


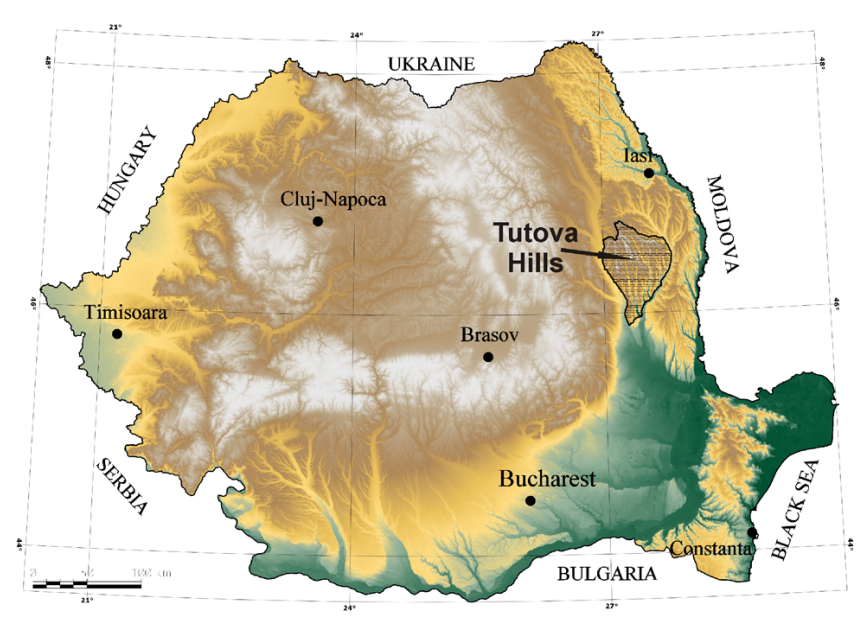

Fig. 1. Location of the study area: Tutova Hills (Eastern Romania).

Barlad Rivers). The landscape of Tutova Hills is grafted on predominantly sandy and sandy-loamy deposits and is characterized by an obvious parallelism of the relatively narrow interfluves. Developed between 46 and $561 \mathrm{~m}$ of altitude, the region presents steep slopes with a fast dynamics of geomorphological processes (mainly sheet erosion and gullying, secondly landslides).

The temperate continental climate is defined by annual mean temperatures between $7.1^{\circ} \mathrm{C}$ and $10.2{ }^{\circ} \mathrm{C}$ and rainfalls that totalize about $500-660 \mathrm{~mm}$ in a year, but which are characterized by an irregular regime. Except the two major bordering rivers and their floodplains, water resources (groundwater and surface water) are modest in terms of quantity and quality, being at the same time strongly influenced by the climatic variability. From the biopedological point of view, the study area is at the limit between the forest domain, dominant in the central-northern part, and the sylvosteppe that occupies the southern part. Isolated, in the low areas along valleys, steppe associations are inserted.

In terms of human geography, Tutova Hills are an exclusively rural region with a low degree of accessibility and an aged population, generally isolated in small villages, without any infrastructure or technical urban facilities. There are 412 villages, mostly of dissociated type, with about 203300 inhabitants, more than $90 \%$ of the active population being occupied in agricultural activities. The agriculture, dominated by crop production, is characterized by the existence of small plots (often of less than one hectare), insufficient mechanization and ignoring the ecological, agrotechnical or economic principles. The region has a peripheral position, both within the five counties (Vaslui, Bacau, Vrancea, Galati, and Neamt) in whose territories it occupies different areas, and in relation to the two major axes of Siret and Barlad valleys. The transport infrastructure is based exclusively on roads, but these ones are poorly modernized and with a low degree of connectivity. Thus, Tutova Hills fall among the least developed regions of Romania, with a high degree of repulsiveness and thus an increased vulnerability of human structures.

On this background, in recent times, Tutova Hills has been (almost without exception) ignored by governmental authorities and permanently avoided by the investors, making infeasible any plans for overall sustainable development of the region. More suitable seems to be the identification of weak points and helping local or regional authorities to intervene on them, allowing at the same time a step by step development. Most frequently, these weak points interfere with the vulnerability factors, as they are presented in the current paper.

Human communities in Tutova Hills have experienced different hazards, natural or human-induced ones, the impact being more and more significant in the two last decades, closely linked to the major changes of Romanian rural society in post-communist era. Being an agricultural region, the main hazards are those related to climate processes that can affect the vital resources of peoples (mainly droughts, hail and heavy rains), but also can isolate entire villages in winter (blizzard). Droughts are the most generalized and the most frequent natural extreme phenomena in the region, affecting the water resources and crop production almost yearly, but having catastrophic consequences once every four or five years. The year 2007 is the most recent example, with very severe drought events that exhausted water resources, field crops and even natural vegetation, many villages remaining without drinking water or food supply, the effect being almost dramatic in the next winter (Stângă, 2009). Hail and heavy rains act rather locally at a given moment, but at least one event occurs yearly in the warm season all over the region, affecting crop yields and causing serious damages, with serious consequences especially for farmers, who have no insurance for their crops. Furthermore, heavy rains exacerbate gully erosion causing enormous soil losses on slopes (Ionita, 2007), dropping the productivity and forcing farmers to abandon their plots on sloping lands. A blizzard occurs every year, especially in January or February, isolating and/or leaving many villages without utilities and supplies, for several days or even one or two weeks (e.g. February 2012). Human-induced hazards have a lower frequency (e.g. accidental fires in dwellings or household annexes etc.), but each time they occur the impact is related to the reduced capacity of society to cope with disaster.

\section{Methodological overview}

Vulnerability assessment requires a multidisciplinary approach, which currently is based on acquisition, adaptation and improvement of methodologies from different fields. For this reason, the efforts have permanently focused on finding a common denominator for all dimensions of vulnerability (exposure, sensitivity, adaptive capacity). In fact, the complexity 
of problems is due to the factors that determine the vulnerability and its global, regional or local forms.

Among the various directions and methods of vulnerability research, building statistical and mathematical indicators is quite frequently used (Villa and McLeod, 2002; Rygel et al., 2006; Peduzzi et al., 2003, 2009; Fekete, 2009; Kappes et al., 2011; Methods for the Improvement of Vulnerability Assessment in Europe, 2011). Adger (2006) points out the existence of four distinct approaches in creating composite indices: elaborating separate indices for each element of vulnerability; construction of unitary indicators by aggregating the relevant parameters; building a single index by defining the geographical context; creating vulnerability profiles for each geographical entity. In relation to these four approaches, the present paper fits the first three, by creating individual indexes for each element of vulnerability, identified according to the regional geographical context and, subsequently, by their integration into a unitary composite index.

More precisely, the present paper aims to assess the vulnerability at regional level for any hazard, the model and the proposed indicators being explicitly intended to quantify the vulnerability of an essentially rural region. Five categories of variables were taken into account to define the vulnerability components: rural habitat, demographic features, agriculture, environmental quality and emergency situations. For each of the five categories, five variables were selected and, thus, the analysis started from 25 variables that might influence the general level of vulnerability. Subsequently, a graph matrix was made to establish the degree of determination or subordination of each variable on a dichotomous query: "Does variable $X$ affect variable $Y$ ?" ("yes" $=1$; "no" $=0$ ). This matrix allows calculating the influence score (IS, the number of variables that are influenced by variable $X$ ) and dependency score (DS, the number of variables by which variable $X$ is influenced). The general level of determination $(D)$ is calculated by the following relation:

$D=\frac{\text { IS-DS }}{n-1}$

where " $n$ " is the number of variables in the matrix. Prioritization of variables according to the obtained values reflects the level of dependence or independence on a scale ranging theoretically between +1 (fully determinant) and -1 (totally determined). In order to ensure the flexibility of the model and to avoid duplication of the analytical criteria in assessing vulnerability, only a single indicator was retained for each category of variables, according to the maximum value calculated through the Eq. (1). Thus, differences between rural communities in the region are very accurately expressed, minimizing the possibility to artificially mosaic the final results (Table 1).

It should be noted that, although there are many approaches based on economical indicators, these ones are not quite relevant for Tutova Hills, and two examples should be expressive. Firstly, the weight of employees is meaningless for the rural context with villages purely based on agriculture; secondly, the average income per capita cannot be used, because most of the population has no income or, if this exists, it is represented by a derisory amount granted as budgetary allocation to older people or children. In some cases, certain economical indicators that could be used do not have a high capacity of discretization and, in case of classification, the entire region would be in a single class. Analyzing the social vulnerability related to floods in Germany, Italy, England and Wales, Kuhlicke et al. (2011) reach the same finding and argue that some classical socio-economic indicators (gender, socio-economic status, employment etc.) have only reduced or even no explanatory capacity. In fact, there are many cases when the usefulness of such indicators depends on how they are contextualized and, thus, related to the natural and human profile of a given area.

All the selected indicators were mathematically processed to maximize the relevance and to unitary express the results in the spread 0-1, " 0 " being assimilated to the minimum vulnerability and "1" corresponding to the maximum vulnerability. Also, the values of each factor were grouped into four classes, corresponding to the level of vulnerability (between 0 and 1): low, medium, high and very high. Thresholds between classes differ from one factor to another, but their meaning is identical. The spatial analysis was based on features of the MicroImages TNTmips 7.3 software, and vulnerability mapping was done by kriging interpolation.

\subsection{Total number of inhabitants (vulnerability factor 1)}

Size of villages influences (directly or indirectly) the development of the proximity services, reflects a certain importance at local level or justifies some investment expenditure (Istrate, 2008). A large settlement requires and develops activities and services that make more efficient the selfadjustment mechanisms and the capacity to cope with crises. On the contrary, small villages have a reduced ability to cope with crisis and their situation seems to be more and more difficult: there are no supply points, schools or medical dispensary and even no car in small villages; there is no accessible road to/from small villages; young people leave small villages forever. For these reasons, it should be accepted that, in this region, the degree of vulnerability evolves inversely with the increasing size of villages. It is interesting to note that the general context was totally different in the past (until the early 20th century) and the population in the small villages of free peasantry was based on own resources, without excessive pressure on them (Muntele, 1998).

Based on the correlation between the size of human settlements and the technical urban facilities, a dimensional threshold was precisely established to allow calculation of the vulnerability factor. Thus, the significance of the threshold is not only statistical, but also a functional one. In the northeast region of Romania, the technical urban facilities of 3016 localities were integrated into a synthetic index with 
Table 1. Categories, variables and selected indicators for vulnerability assessment (with bold line: the highest values of each category and the selected variables).

\begin{tabular}{|c|c|c|c|}
\hline Category & Variables & $D$ & Indicator \\
\hline Rural habitat & $\begin{array}{l}\text { Number of households } \\
\text { Type of constructions } \\
\text { Total population } \\
\text { Technical urban facilities } \\
\text { Existence of schools }\end{array}$ & $\begin{array}{l}-0.0833 \\
+0.0417 \\
+\mathbf{0 . 4 1 6 7} \\
-0.2917 \\
-0.0417\end{array}$ & Total number of inhabitants \\
\hline Demography & $\begin{array}{l}\text { Age groups structure } \\
\text { Gender structure } \\
\text { Proportion of employed people } \\
\text { Schooling rate } \\
\text { Health status of population }\end{array}$ & $\begin{array}{l}+\mathbf{+ 0 . 3 3 3 3} \\
+0.0002 \\
-0.0417 \\
-0.1667 \\
-0.3333\end{array}$ & Dependency ratio \\
\hline Agricultural economy & $\begin{array}{l}\text { Profitability of farming system } \\
\text { Average income per capita } \\
\text { Farm size } \\
\text { Total weight of arable land } \\
\text { Weight of arable land on slopes }\end{array}$ & $\begin{array}{l}-0.0833 \\
-0.1250 \\
+0.0002 \\
-0.0417 \\
+\mathbf{0 . 1 6 6 7}\end{array}$ & Weight of arable land on slope categories \\
\hline Environment quality & $\begin{array}{l}\text { Pollution sources } \\
\text { Soil erosion } \\
\text { Quality of water resources } \\
\text { Weight of land under forestry } \\
\text { Waste management }\end{array}$ & $\begin{array}{l}0.0000 \\
-0.1667 \\
-0.0417 \\
+\mathbf{0 . 1 2 5 0} \\
0.0000\end{array}$ & Weight of land under forestry \\
\hline Emergency services & $\begin{array}{l}\text { Existence of emergency services } \\
\text { Distance from the nearest town } \\
\text { Quality of communication lines } \\
\text { Frequency of transport } \\
\text { Number of private cars }\end{array}$ & $\begin{array}{l}-0.1667 \\
+\mathbf{0 . 5 4 1 7} \\
+0.0833 \\
-0.0417 \\
-0.0833\end{array}$ & Road accessibility of villages \\
\hline
\end{tabular}

values ranging from 0 to 100 (Tudora, 2010), but it is difficult to obtain a good correlation between this index and the size of settlements, due to the complexity of factors that impose certain facilities. Especially to emphasize this relation, the database was verified and filtered through statistical methods: analysis of regression residues and standard deviation tolerance applied to the ratio between total population and aforementioned statistical index. This methodological approach led the authors to exclude from the database the peri-urban settlements and tourist resorts. In the first case, the peri-urban settlements are, most frequently, peripheral town districts and the development of their technical facilities is a natural consequence of urban system evolution. In fact, these settlements may be, apparently, independent, but they are functionally dependent and integrated in neighbouring cities (Istrate, 2008). Furthermore, there is no periurban settlement in our study area. In the second case, the tourist resorts have a special status, their facilities being designed to meet the needs of a segment of population that come from outside and for a clearly limited period of time. Almost all these tourist resorts are located in the mountain area, being totally absent in the hilly area of Eastern Romania (not only Tutova Hills). For the remaining 2776 localities, with a total population that ranges between 1 and more than 300000 inhabitants, the correlation between the two indicators is defined by a logarithmic function $\left(R^{2}=0.214\right)$. Secondly, after the ascending ordering of settlements according to the number of inhabitants, the data string has been divided into 31 equidimensional classes. For these classes, the statistical coefficient of correlation is more than representative: $R^{2}=0.911$. The graphical representation was done in logarithmic scale to allow a more expressive data view (Fig. 2).

Analyzing this index, which expresses the quality and quantity of technical urban facilities, it must be noted that the values ranging from 13 to 20 characterize both the best equipped villages and the worst equipped towns. For this reason, the value of 13 was considered a reference threshold, corresponding to the minimum vulnerability of villages in terms of technical urban facilities. Based on the regression equation, the maximum reference threshold in terms of settlement size was set to 9500 people. Practically, the assumed premise is that a village of 9500 inhabitants (reference population) has sufficient facilities to cope independently with some crises. The vulnerability factor is quantified through the following formula: 


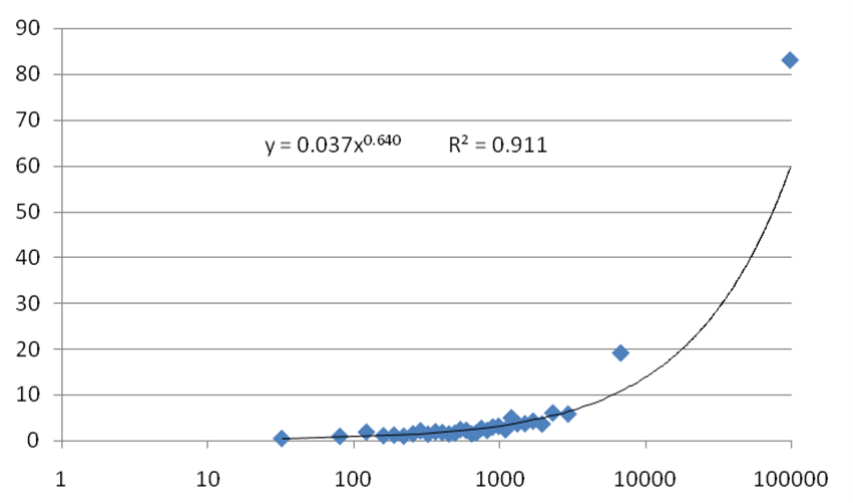

Fig. 2. Correlation between the index of technical urban facilities (vertical axis) and settlements population (horizontal axis, logarithmic scale).

$\mathrm{Vf}_{1}=\left[\frac{P_{\mathrm{ref}}-P_{i}}{P_{\mathrm{ref}}}\right]^{10}$

where $\mathrm{Vf}_{1}$ is the vulnerability factor 1 [0-1], $P_{\text {ref }}$ is the reference population, and $P_{i}$ is the village's population. "10" is a corrective coefficient, whose value was established by successive statistical testing and which depends mainly on the maximum value of $P_{i}$. This corrective coefficient was applied both to enhance the relevance of vulnerability factor of each village and to ensure an optimal distribution in the spread 0-1. Reconsidering the relation between the technical urban facilities, the settlement size and the vulnerability factor, values of the last were grouped into four classes as follows: low vulnerability $(\leq 0.40)$; medium vulnerability (0.41-0.60), high vulnerability $(0.61-0.80)$ and very high vulnerability $(>0.80)$.

\subsection{Dependency ratio (vulnerability factor 2)}

The dependency ratio renders the relationship between children (0-14 yr) and elderly ( $\geq 65 \mathrm{yr})$, on the one hand, and the active population (15-64 yr), with major responsibilities in ensuring the necessary living support, on the other hand. Socio-economic indicator used by the World Bank, the dependency ratio can reflect the response capacity of a community facing various crises, being an expression of the number that active or potentially active population has to support (Johnston, 1994).

Usually it is expressed as a percentage (under or over $100 \%$ ), but in the current context, the decimal values are used. The basic formula is

Dr $=\frac{P_{0-14}+P_{\geq 65}}{P_{15-64}}$

where Dr is the dependency ratio and $P_{0-14}, P_{\geq 65}$, and $P_{15-64}$ express the number of people aged of the subscript years. To calculate the vulnerability factor, the dependency ratio was transformed using the following equation:

$\mathrm{Vf}_{2}=\frac{\mathrm{Dr}^{2}}{\mathrm{Dr}^{2}+1}$.

Thus, the initial values are redistributed in the spread 0-1 and the level of significance increases, the relation between the dependency ratio and the vulnerability factor being well described by an exponential function $\left(R^{2}=0.978\right)$. That is why the classification of vulnerability according to this factor must be made starting from a mid theoretical value: low vulnerability $(\leq 0.40)$; medium vulnerability $(0.41-0.50)$, high vulnerability $(0.51-0.60$ and very high vulnerability $(>0.60)$.

\subsection{Corrected weight of arable land (vulnerability factor 3)}

Arable lands occupy 124471 hectares in Tutova Hills, meaning $36.46 \%$ of their total area, which, in relation to the number of inhabitants, represents 0.61 hectares per capita. These lands are unevenly and inappropriately distributed on slopes, which contributes to minimizing agricultural production and to increasing soil erosion. For the physical-geographical conditions of Tutova Hills, slope is the main limiting factor for the use of arable land (Niacsu, 2009). Furthermore, although the weight of arable land decreases, the number of Lilliputian-sized farms gradually grows together with slope increasing (Stângă, 2009). In our research region, there are over 150000 arable plots with an average area under a hectare, but in the central-northern part of region, with a higher landform fragmentation, the real situation is the most difficult (the average area of the plots is under 0.5 hectares), and only in the south and southeast, there are a few larger farms (over 10 hectares). On such a background, calculating the weight of arable land on different categories of slope becomes more relevant, but it requires a broader approach: establishing the reference spatial units, realization and classification of slope map, the land use map overlay and, finally, the statistical data extraction. The weight of arable land on slope categories was calculated for the 412 Voronoi polygons that resulted by splitting the research area based on distances between villages. The slope map was realized through spatial manipulation language based on digital elevation model $(\mathrm{DEM})$, with a pixel resolution of $30 \times 30 \mathrm{~m}$. Arable land distribution was analyzed starting from the Corine Land Cover vector database (2006), which was corrected and completed using orthorectified aerial images for a higher level of detail. The used software allows calculating automatically the weight of different slope categories and, subsequently, the weight of arable land for each slope category, as they appear in the Eq. (5). The vulnerability factor is based on the equation below: 
Table 2. Synthetic data of vulnerability factor 1 in Tutova Hills.

\begin{tabular}{llrrrrr}
\hline \multirow{2}{*}{ Vulnerability class } & & $\begin{array}{r}\text { Low } \\
\text { vulnerability }\end{array}$ & $\begin{array}{r}\text { Medium } \\
\text { vulnerability }\end{array}$ & $\begin{array}{r}\text { High } \\
\text { vulnerability }\end{array}$ & $\begin{array}{r}\text { Very high } \\
\text { vulnerability }\end{array}$ \\
\cline { 1 - 3 } \cline { 5 - 7 } Inhabitants & Class limits & & $5470-841$ & $811-467$ & $454-204$ & 203 \\
& Average per village & & 1551 & 602 & 308 & 105 \\
& Total number & & 102354 & 46380 & 39758 & 14766 \\
& Percentage (\%) & & 50.36 & 22.82 & 19.56 & 7.26 \\
\hline \multirow{2}{*}{ Villages } & Number & 66 & 77 & 129 & 140 \\
& Percentage (\%) & 16.02 & 18.69 & 31.31 & 33.98 \\
\hline
\end{tabular}

$\mathrm{Vf}_{3}=$

$\left[\frac{0.05 \times A_{1}+0.10 \times A_{2}+0.15 \times A_{3}+0.35 \times A_{4}+0.60 \times A_{5}+0.95 \times A_{6}}{100}\right]^{2}$

where $A_{1}$ is the weight of arable land on slopes below $1^{\circ}$; $\mathrm{A}_{2}$ is the weight of arable land on slopes of $1-3^{\circ} ; A_{3}$ is the weight of arable land on slopes of $3-5^{\circ} ; A_{4}$ is the weight of arable land on slopes of $5-10^{\circ} ; A_{5}$ is the weight of arable land on slopes of $10-15^{\circ} ; A_{6}$ is the weight of arable land on slopes over $15^{\circ}$. The weighting coefficients were estimated according to data from scientific literature concerning the flow rate and hence the soil loss on slopes in the region's bio-pedoclimatic conditions (Moţoc et al., 1975; Popa, 1999; Morgan, 2005). Thus, for each Voronoi polygon a unique value is obtained, which is assigned to the corresponding village. This vulnerability factor expresses the actual distribution of arable land on slope categories to an optimal distribution that would best capitalize the agricultural system and would minimize soil losses. It must still be kept in mind that the factor does not take into account the total area of arable lands, but only their distribution. Vulnerability classes were separated by thresholds established through correlation of land evaluation system, currently in force in Romania. Thus, the four classes are low vulnerability $(\leq 0.20)$, medium vulnerability $(0.21-0.40)$, high vulnerability $(0.41-0.60)$ and very high vulnerability $(>0.60)$.

\subsection{Weight of land under forestry (vulnerability factor 4)}

Weight of land under forestry area is one of the indicators commonly used to assess the state of environment quality. As zonal bioclimatic association, a forest belongs structurally and functionally to natural environment, having an essential role in maintaining the systemic equilibrium. The fragility of the equilibrium relations and hence vulnerability of the humanized territory increase together with the reduction of forested surfaces. To this, it can be added the fact that wood is the main building material for more than $50 \%$ of houses and heating fuel for more than $75 \%$ of rural households in the research region. The vulnerability factor was calculated for each Voronoi polygon previously delineated. The basic formula is

$\mathrm{Vf}_{4}=\left[1-\frac{\mathrm{FA}}{\mathrm{TA}}\right]^{2}$

where FA is the forested area within the polygon and TA is the total polygon area. The power function increases the relevance of values and their capacity of discretization. The forestry areas were separated using Corine Land Cover 2006, with the same corrections and completions applied in the case of arable lands.

On the basis of the Eq. (6), the results theoretically vary between 0 ( $100 \%$ forest) and 1 ( $0 \%$ forest). In Tutova Hills, forests (natural or planted) occupy 73416 hectares, representing $21.46 \%$ of the region. On the basis of soil properties, some previous studies (Niacşu and Stângă, 2006; Niacşu, 2009; Stângă, 2009) suggest an initial weight of forestry up to $70 \%$ of the total region. This issue requires a correction of Eq. (6):

$\mathrm{Vf}_{4}=\left[1-\frac{\mathrm{FA}}{0.7 \times \mathrm{TA}}\right]^{2}$

According to the results of Eq. (7), vulnerability classes were defined as follows: low vulnerability $(\leq 0.50)$, medium vulnerability $(0.51-0.70)$, high vulnerability $(0.71-0.90)$ and very high vulnerability $(>0.90)$.

\subsection{The road accessibility of villages (vulnerability factor 5)}

With only very few exceptions, villages in the region do not have their own means of intervention in emergency situations (ambulance, fire equipment, snow removal machines, high capacity pumping stations etc.) and the crisis management cannot be guaranteed without the support of specialized units in neighbouring cities. Therefore, distance to the nearest urban center is a key element in assessing the accessibility of emergency services and it is the best indicator of the deeply rural character or of the high degree of isolation. But can this static distance be planned to reduce vulnerability? In Romania, before 1990, communist authorities had tried to relocate 
Table 3. Synthetic data of vulnerability factor 2 in Tutova Hills.

\begin{tabular}{clrrrrr}
\hline \multirow{2}{c}{$\begin{array}{c}\text { Vulnerability } \\
\text { class }\end{array}$} & & $\begin{array}{r}\text { Low } \\
\text { vulnerability }\end{array}$ & $\begin{array}{r}\text { Medium } \\
\text { vulnerability }\end{array}$ & $\begin{array}{r}\text { High } \\
\text { vulnerability }\end{array}$ & $\begin{array}{r}\text { Very high } \\
\text { vulnerability }\end{array}$ \\
\hline \multicolumn{2}{c}{ Dependency ratio } & & $\leq 0.82$ & $0.82-1.01$ & $1.02-1.23$ & $>1.23$ \\
\cline { 1 - 4 } Inhabit. & Total number & & 73760 & 82646 & 35976 & 10876 \\
\cline { 5 - 7 } & Percentage (\%) & & 36.3 & 40.7 & 17.7 & 5.4 \\
\hline \multirow{2}{*}{ Villages } & Number & & 78 & 170 & 101 & 63 \\
& Percentage (\%) & 18.9 & 41.3 & 24.5 & 15.3 \\
\hline
\end{tabular}

Table 4. Synthetic data of vulnerability factor 3 in Tutova Hills.

\begin{tabular}{clrrrrr}
\hline \multirow{2}{c}{$\begin{array}{c}\text { Vulnerability } \\
\text { class }\end{array}$} & & $\begin{array}{r}\text { Low } \\
\text { vulnerability }\end{array}$ & $\begin{array}{r}\text { Medium } \\
\text { vulnerability }\end{array}$ & $\begin{array}{r}\text { High } \\
\text { vulnerability }\end{array}$ & $\begin{array}{r}\text { Very high } \\
\text { vulnerability }\end{array}$ \\
\hline \multicolumn{2}{c}{ Area (\% of total area) } & & 12.65 & 25.92 & 37.16 & 24.27 \\
\cline { 1 - 3 } \cline { 4 - 6 } Inhabit. & Total number & & 52710 & 50158 & 58965 & 41425 \\
& Percentage (\%) & & 25.9 & 24.7 & 29.0 & 20.4 \\
\hline \multirow{2}{*}{ Villages } & Number & & 65 & 84 & 141 & 122 \\
& Percentage (\%) & 15.8 & 20.4 & 34.2 & 29.6 \\
\hline
\end{tabular}

by force villages or had convinced the working rural population to move in towns in a supposed effort to systematize country and to support the massive planned industrialization. Later, post-communist governments tried to redesign artificially the Romanian urban system by granting some greater villages with urban status. Both solutions to reduce distance between rural settlements and towns (relocation of villages or declaring some of them as having urban status) failed and are not feasible for vulnerability assessment. For the latter purpose, the authors transformed the conventional distances by replacing the metric system of reference by new operational one, based on time-distances. In this approach, accessibility reduces and vulnerability increases progressively with the growing difference between operational and functional distances emphasizing those sectors where investments are absolutely necessary.

On the basis of orthorectified aerial images (2005 edition, scale 1:5000, and pixel size $0.5 \times 0.5 \mathrm{~m})$, the distances between the 412 villages in the region and the neighbouring towns were calculated in order to identify the most accessible way. Also, a sectoral analysis was made and the real distances were corrected according to the quality of the road network. Thus, for each category of road, an operational distance was obtained as product between the real distance and a correction coefficient. The operational distance between any village and the nearest town is the sum of sectoral operational distances, as in the Eq. (8):
$\mathrm{Od}=\alpha_{1} \times d_{1}+\alpha_{2} \times d_{2}+\ldots+\alpha_{n} \times d_{n}=\sum_{i=1}^{n} \alpha_{i} \times d_{i}$

where "Od" is the operational distance between villages and the nearest town, " $\alpha_{i}$ " is the correction coefficient and " $d_{i}$ " is the real distance for each sector of road. In this study, the following categories of roads and the related weightings were used: European road: $\alpha=1.0$; national road: $\alpha=1.1$; modernized county road: $\alpha=1.2$; partly modernized road: $\alpha=1.3$; unmodernized road with great difficulties of access: $\alpha=1.5$. The weighting factors were established based on the time necessary to travel a standard distance, through the following equation:

$\alpha_{i}=\frac{t_{i}}{T}$

where $\alpha_{i}$ is the correction coefficient for a road of " $i$ " category and; $t_{i}$ is the time necessary to travel a certain distance on a road of " $i$ " category; $T$ is the time necessary to travel the same distance at an average speed of $60 \mathrm{~km} / \mathrm{h}$. This speed was considered because it represents the average speed of emergency vehicles, according to the Order no. 360/2004 of the Romanian Minister of Administration and Internal Affairs. The investments in infrastructure reduce together with the increasing distance between towns and villages and the degree of isolation, which is accurately reflected in quality of roads. For this reason, due to the cumulative effect, the operational distances become progressively larger than the real ones. Based on data of the 412 villages in Tutova Hills, the statistical relation between the two types of distance is well described by Eq. (10) and the results are applicable for real distances up to $75 \mathrm{~km}$ : 
$\mathrm{Od}=\left[\sum_{i=1}^{n} d_{i}\right]^{1.098}$

To quantify the vulnerability factor, the starting point is that vulnerability increases together with the operational distance between the rural localities and the neighbouring towns. Considering that a village located at a distance of $100 \mathrm{~km}$ from the nearest town is completely isolated, the vulnerability factor was calculated on the basis of Eq. (11):

$\mathrm{Vf}_{5}=\frac{\mathrm{Od}}{100}$.

According to the aforementioned Order no. 360/2004, the medium range of action for the professional emergency services must be, at least theoretically, of $15-30 \mathrm{~km}$. Thus, for an individual analysis of this vulnerability factor, the four classes were separated as follows: low vulnerability $(\leq 0.15)$, medium vulnerability $(0.16-0.30)$, high vulnerability $(0.31-$ $0.45)$ and very high vulnerability $(>0.45)$.

\subsection{General vulnerability index}

The integration of the vulnerability factors in a single vulnerability index (composite index) was tested through various methods to check the errors introduced into the synthesis results: weighted arithmetic mean, square mean, harmonic mean, rank sum etc. The optimal alternative was finally based on the geometric mean due to a double relation. Firstly, the logarithm of the geometric mean is the sum of factor logarithms, and, secondly, the logarithm function is the inverse of the exponential one, which best describes the relation between the level of vulnerability and the considered cumulative variables. Furthermore, since 2010, United Nations Human Development Index is calculated by a new method, based on the same geometric mean (UNDP, 2010). The basic equation of general vulnerability index (GVI) is

$\mathrm{GVI}_{i}=\sqrt[5]{\mathrm{Vf}_{1} \times \mathrm{Vf}_{2} \times \mathrm{Vf}_{3} \times \mathrm{Vf}_{4} \times \mathrm{Vf}_{5}}$.

To obtain a higher significance at the regional level of Tutova Hills, the maximum value of GVI is extracted from the data string and used to apply a regional correction that redistributes the values in the spread 0-1. Thus, Eq. (12) becomes

$\mathrm{GVI}=\frac{1}{\mathrm{GVI}_{\max }} \times \mathrm{GVI}_{i}=\frac{1}{0.778353} \times \mathrm{GVI}_{i}=1.2848 \times \mathrm{GVI}_{i}$.

\subsection{Results and discussion}

The villages in Tutova Hills have a population that falls between the minimum (one) and 5470 inhabitants, but most of them $(88.35 \%)$ do not exceed the threshold of 1000 inhabitants. Most of the villages do not have any technical urban facilities, except electricity, and only those with residence status have certain common utilities. Moreover, large villages

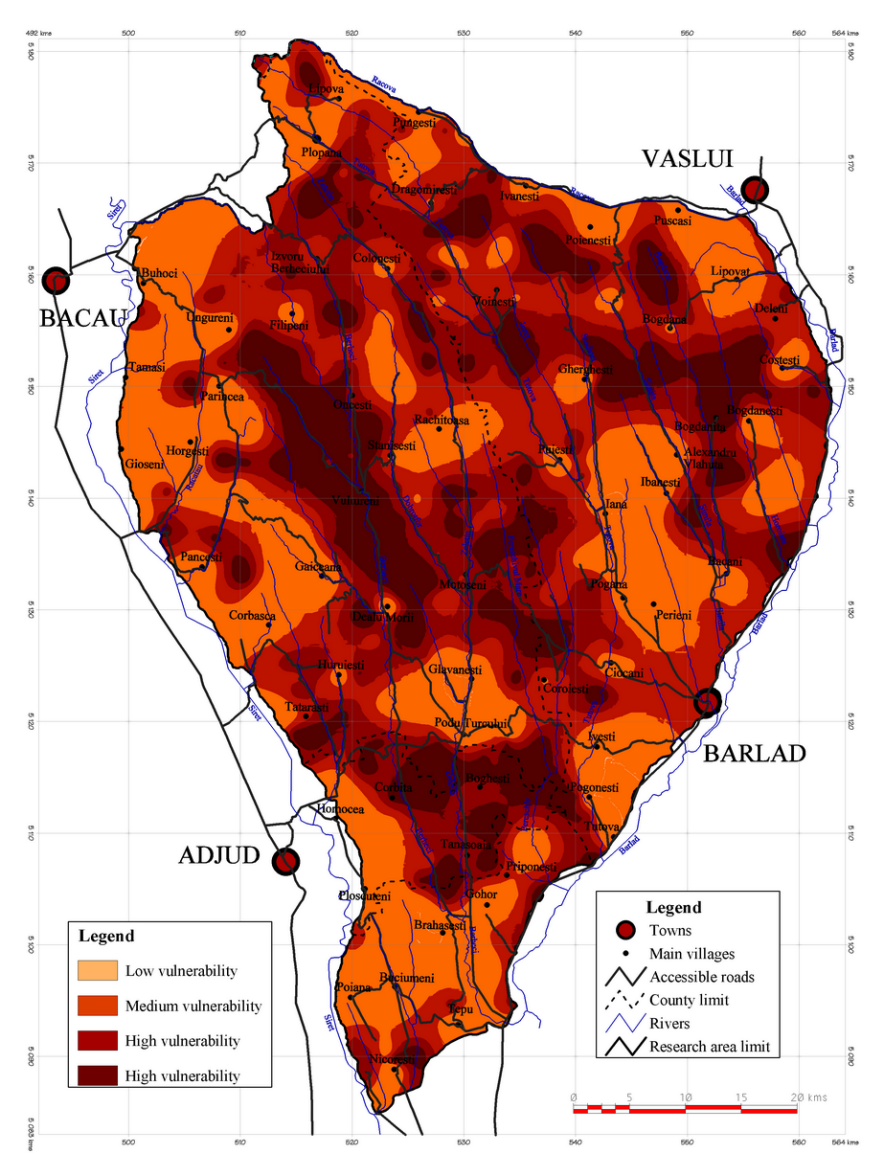

Fig. 3. Vulnerability factor 1: Size of villages (number of inhabitants) in Tutova Hills.

are connected by means of public transport to the neighbouring towns.

Analyzing the values of vulnerability factor 1 (Eq. 2), it must be noted that $65.92 \%$ of villages with $26.28 \%$ of the total population are characterized by high and very high vulnerability. These are the very small villages, not exceeding 460 inhabitants (Table 2). Most of them are concentrated in the central part of Tutova Hills (Fig. 3), the limitation of their development being imposed both by the restrictive geographical position and the development policies in the communist regime (1945-1989), with some implications up until now.

With respect to the vulnerability factor 2 , age structure of population is quite heterogeneous, with values falling in the gap 0.24-4.17 (24-417\%). From this point of view, the dependency ratio shows that $39.8 \%$ of villages with $23.1 \%$ of population are characterized by high and very high vulnerability (Table 3). The research region is highly mosaic because of two distinct situations rendered by the same index. Firstly, it is the existence of small villages with aging population, in the central-northern part of the region, especially in the middle and upper valleys of the rivers. Compared to a general average size of 493 inhabitants, the villages highly and very highly vulnerable in terms of dependency ratio have an 
Table 5. Synthetic data on vulnerability factor 4 in Tutova Hills.

\begin{tabular}{|c|c|c|c|c|c|}
\hline \multicolumn{2}{|c|}{$\begin{array}{l}\text { Vulnerability } \\
\text { class }\end{array}$} & $\begin{array}{r}\text { Low } \\
\text { vulnerability }\end{array}$ & $\begin{array}{r}\text { Medium } \\
\text { vulnerability }\end{array}$ & $\begin{array}{r}\text { High } \\
\text { vulnerability }\end{array}$ & $\begin{array}{l}\text { Very high } \\
\text { vulnerability }\end{array}$ \\
\hline \multicolumn{2}{|c|}{ Percentage of forestry $(\%)$} & $>29$ & $29-16$ & $16-5$ & $<5$ \\
\hline \multirow{2}{*}{ Inhabitants } & Total number & 52867 & 36222 & 64126 & 50043 \\
\hline & Percentage $(\%)$ & 26.01 & 17.82 & 31.55 & 24.62 \\
\hline \multirow{2}{*}{ Villages } & Number & 94 & 80 & 122 & 116 \\
\hline & Percentage $(\%)$ & 22.82 & 19.42 & 29.61 & 28.16 \\
\hline
\end{tabular}

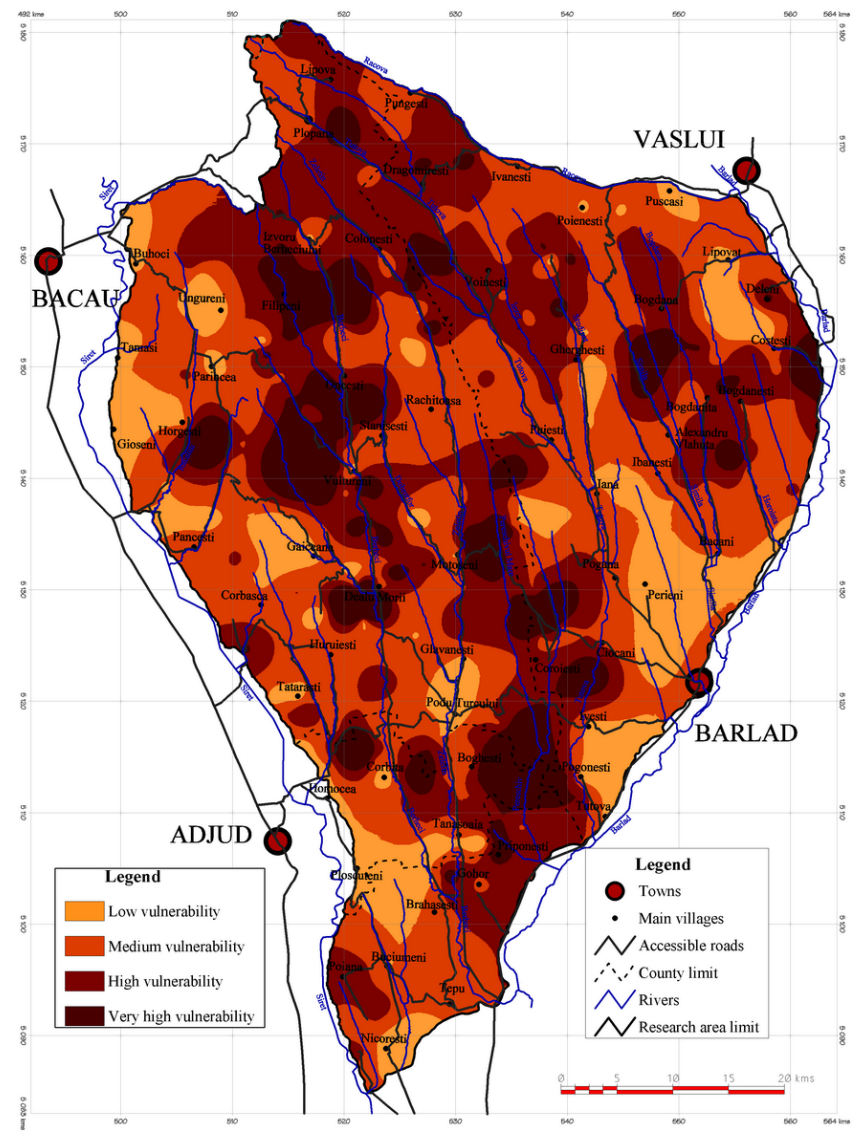

Fig. 4. Vulnerability factor 2: Population dependency ratio in Tutova Hills.

average size of 356 and, respectively, 173 inhabitants. Secondly, there are also some large villages characterized by high vulnerability, given the great number of children. The major difference is that villages in the latter category have the perspective of balancing the degree of dependence on short and medium term, while in the case of small villages, in the first category, demographic decline and increasing dependency will keep the same trend line (Fig. 4).

With regard to vulnerability factor 3 (weight of arable lands on slope categories), it should be noted that the region's economy is based largely on crop production, and arable land

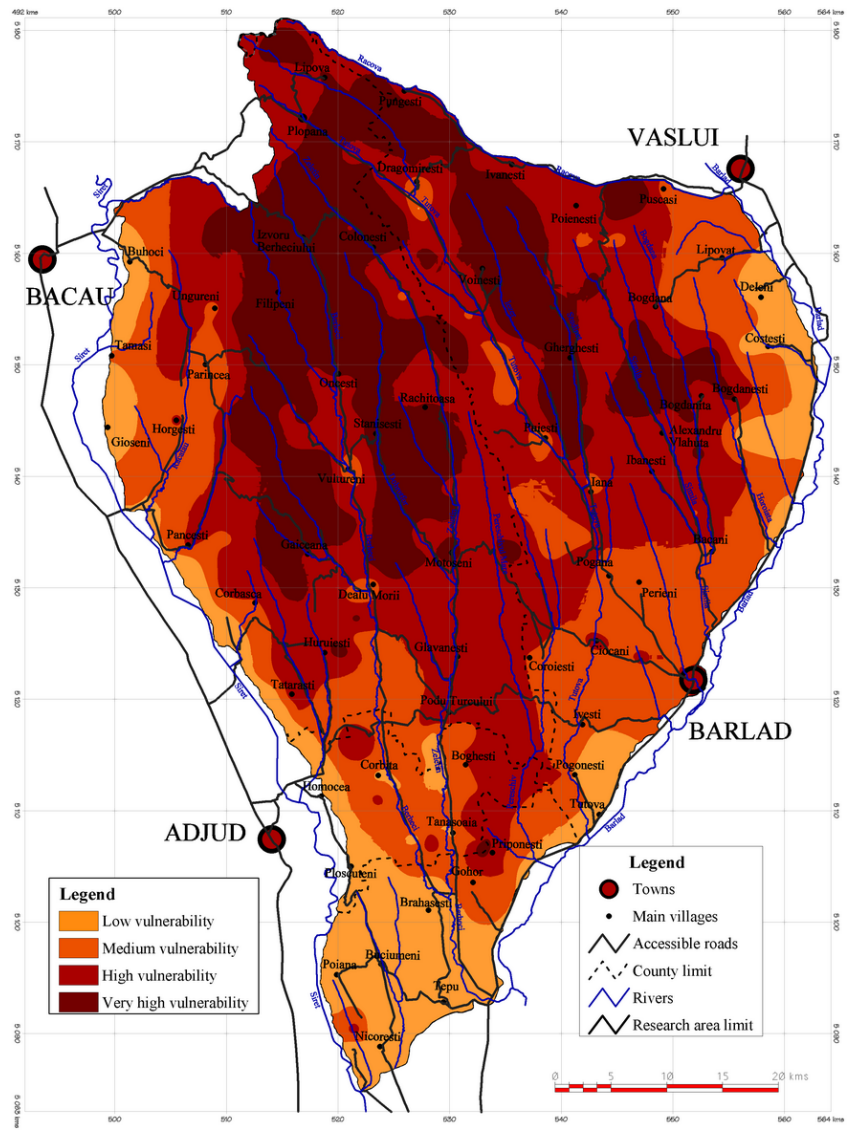

Fig. 5. Vulnerability factor 3 : Percentage of arable lands on slopes in Tutova Hills.

distribution on slope categories summarizes the situation of a subsistential agriculture. According to vulnerability factor 3 , $61.42 \%$ of Tutova Hills ( $63.8 \%$ of villages with $49.4 \%$ of total population) is characterized by an improper land use and thus by a high and very high vulnerability from this point of view (Table 4 and Fig. 5).

Regarding vulnerability factor 4 , it must be noted that weight of land under forestry is currently $19.8 \%$, much narrower than the percentage in natural conditions, which was assessed at about $65-70 \%$. The climate and morphological features required some differences in natural forest 


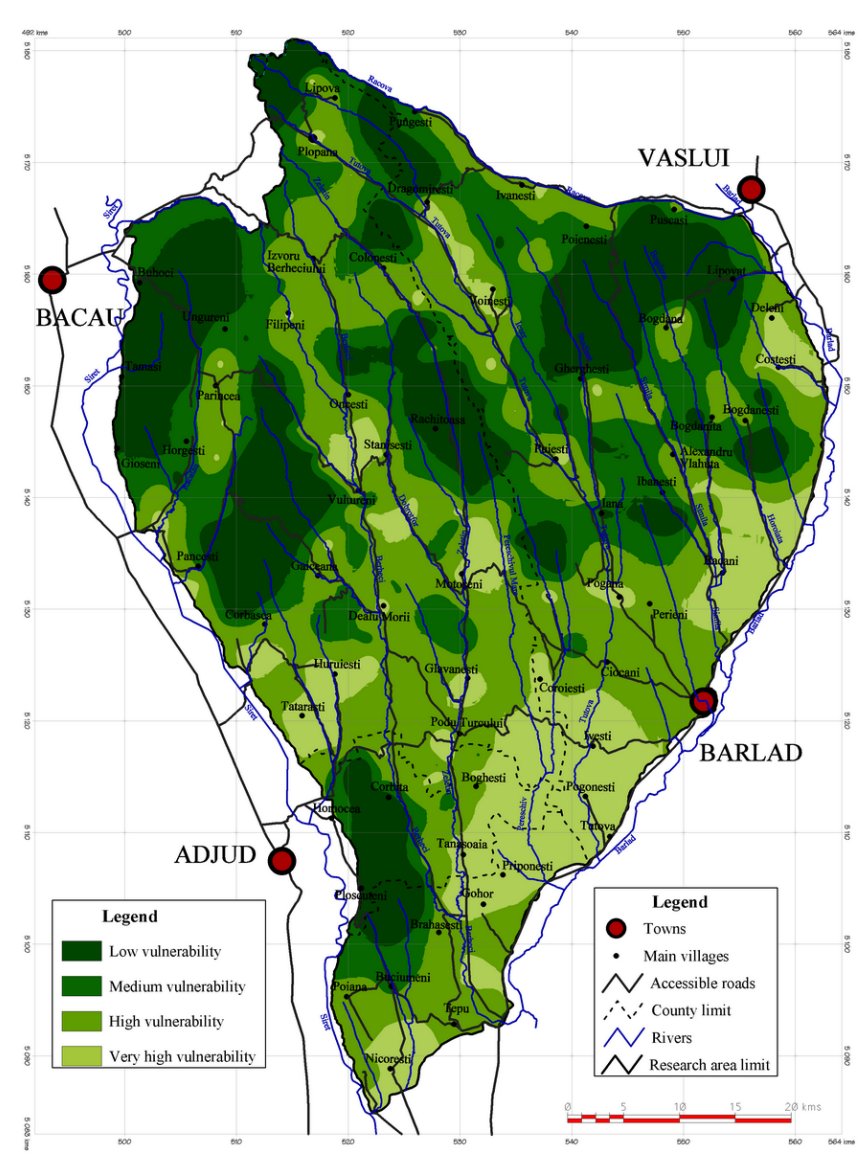

Fig. 6. Vulnerability factor 4: Weight of land under forestry in Tutova Hills.

distribution, from under $40 \%$ in the southern region to over $80 \%$ in the central-north area, but the current distribution is almost entirely imposed by the age, type and intensity of human activity.

The analysis of this vulnerability factor shows that $46.77 \%$ of the territory ( $57.77 \%$ of villages and $56.17 \%$ of population) is characterized by high and very high vulnerability (Table 5). In these classes of vulnerability, two distinct situations can be identified: firstly, villages near the Barlad valley, which formed, over time, an important axis of movement, and, secondly, the area within the region, with ancient villages of free peasantry. At the opposite extreme, there are many areas with low and medium vulnerability. Typical situations are those in which the forests survived, especially in the north-central areas, with high fragmentation, but lower human pressure. Secondly, lower values are due to afforestation and ecological restoration in the 8th and 9th decades of 20th century. Comparing the four classes of vulnerability, it should be noted that vulnerability factor 4 emphasizes more clearly the regional differences, from low vulnerability, where forestry occupies $41.9 \%$, to very high vulnerability, where the percentage is reduced to $1.69 \%$ on average (Fig. 6).

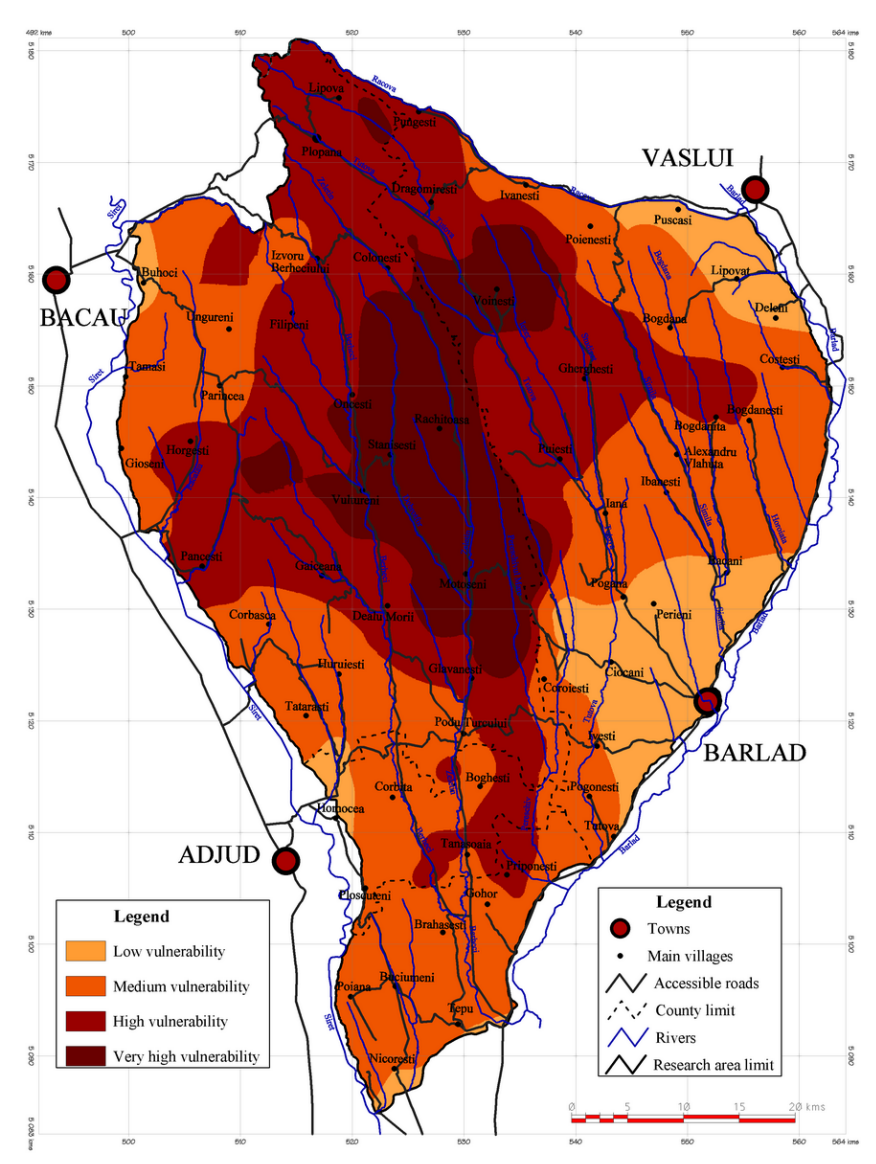

Fig. 7. Vulnerability factor 5: Road accessibility of villages in Tutova Hills.

Finally, vulnerability factor 5 reveals the road accessibility of villages in Tutova Hills, by means of operational distances presented in the previous chapter. The territory is less mosaic, and the four zones of vulnerability have a roughly concentric distribution around the center, on the limit between the counties of Vaslui and Bacau. This boundary area creates a real "border effect" that causes many functional problems for the local and regional development, including by inhibiting expansion and modernization of communication ways. Overall, $48.44 \%$ of territory (51.44\% of villages, namely $35.92 \%$ of the population) corresponds to the areas with high and very high vulnerability (Table 6 and Fig. 7). Furthermore, it must be pointed out that the villages characterized by very high vulnerability are at an average distance of $58.7 \mathrm{~km}$ to the nearest town, but there are 14 villages located over $70 \mathrm{~km}$ away, completely isolated, especially since they are not connected at the transportation network.

The integration of vulnerability factors in the general vulnerability index creates a summary image of the research region. Data show that over $50 \%$ of territory is assimilated to areas with high and very high human vulnerability (Fig. 8 and Table 7). In addition, it may be established a good correlation between the average values of vulnerability factors and 
Table 6. Synthetic data on vulnerability factor 5 in Tutova Hills.

\begin{tabular}{|c|c|c|c|c|c|}
\hline \multicolumn{2}{|c|}{$\begin{array}{l}\text { Vulnerability } \\
\text { class }\end{array}$} & $\begin{array}{r}\text { Low } \\
\text { vulnerability }\end{array}$ & $\begin{array}{r}\text { Medium } \\
\text { vulnerability }\end{array}$ & $\begin{array}{r}\text { High } \\
\text { vulnerability }\end{array}$ & $\begin{array}{l}\text { Very high } \\
\text { vulnerability }\end{array}$ \\
\hline \multicolumn{2}{|c|}{ Operational distance $(\mathrm{km})$} & $\leq 0.15$ & $0.16-0.30$ & $0.31-0.45$ & $>0.45$ \\
\hline \multirow{3}{*}{ Inhabitants } & Total number & 33359 & 98352 & 52621 & 21178 \\
\hline & Average per village & 981 & 582 & 358 & 311 \\
\hline & Percentage $(\%)$ & 16.23 & 47.86 & 25.61 & 10.31 \\
\hline \multirow{2}{*}{ Villages } & Number & 34 & 169 & 147 & 68 \\
\hline & Percentage (\%) & 8.13 & 40.43 & 35.17 & 16.27 \\
\hline
\end{tabular}

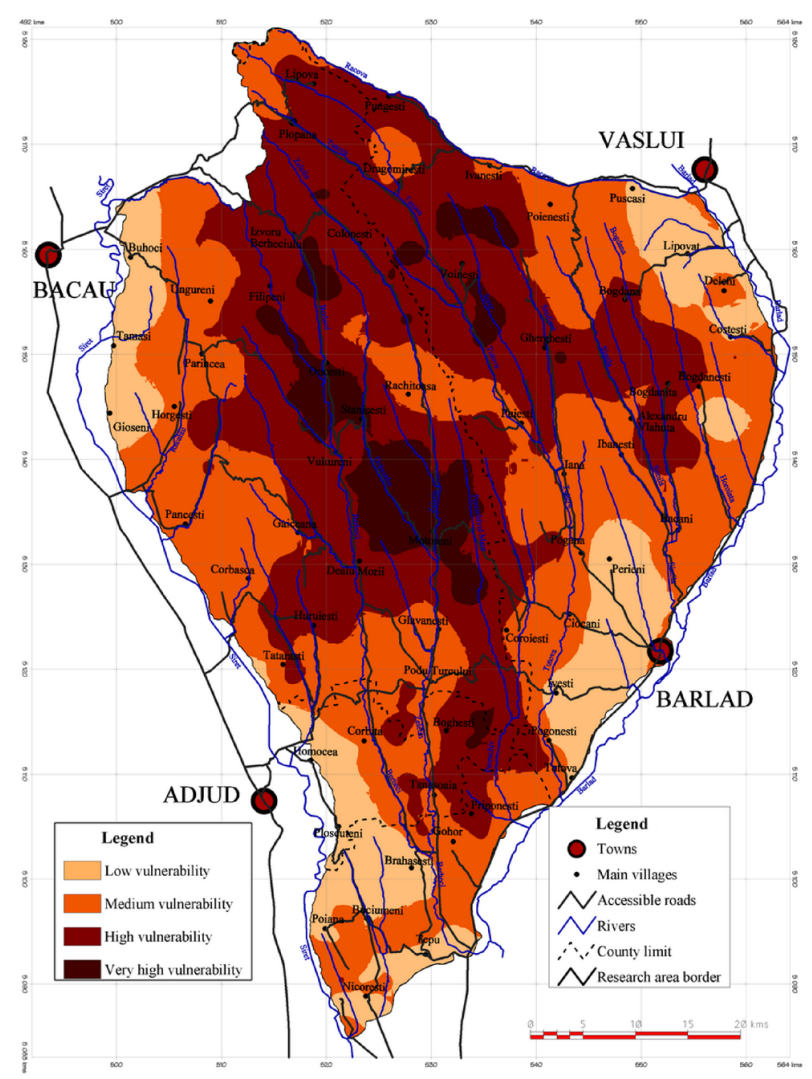

Fig. 8. General vulnerability index in Tutova Hills.

the general vulnerability index, except for factor 4, which has a different distribution, as explained above.

Some of these indicators can be related to the quick impact hazards (emergency services through the road accessibility), while others can be associated to hazards with cumulative impact (subsistential farming system, environmental fragility). Thus, the synthetic index provides a suggestive image of the regional vulnerability profile, combining different contextualized indicators.

\section{Conclusions}

The identification, quantification and spatialization of weaknesses and system failures or dysfunctions through vulnerability assessment can be a starting point both for risk mitigation and realization of sustainable development plans adapted to real possibilities, capabilities and adaptabilities of any region. Although there are some general factors that may influence the degree of vulnerability in any frame and to any level of analysis, this paper shows that vulnerability assessment can be made only by identifying and integrating indicators compatible with the analysis level and the geographic, economic and social features of a certain region. The proposed indicators and their mathematical calculation aim to render as accurately as possible the existing differences between rural communities in the research area, and also to minimize artificial differentiations and, thus, to avoid inconclusive results. The indicators allow the structural and functional analysis of vulnerability and enable the identification of weaknesses and of the potential imbalances at local and regional level. Integrating vulnerability factors in a synthetic index gives an overview that allows hierarchies and comparisons on different levels and creates the vulnerability profile of the studied geographical unit. The transfer of the model to another region (hilly area or not, rural space or not) can be easily realized, but it will be feasible only after a review of indicators and weighting coefficients, according to the working scale, region profile and data availability. In context of environmental global changes, increasing soil losses on slopes may be a key element in agricultural regions, but could have reduced significance or no significance in other cases (e.g. plains with low slopes or non-agricultural regions). In the same way, for example, road accessibility of villages is in this case an important indicator, but in more developed countries, selection of variables would probably bring in the foreground the presence and the quality of emergency services. Thus, in the authors' opinion, for a general and flexible model to be applied elsewhere, vulnerability assessment must be related to natural or human conditions of a region ("place vulnerability", cf. Cutter, 1996). This does not limit the possibility of structural, functional or spatial comparisons, since the selected indicators (in this case, total population of villages, dependency 
Table 7. Synthetic data on vulnerability in Tutova Hills.

\begin{tabular}{clrrrrr}
\hline $\begin{array}{c}\text { Vulnerability } \\
\text { class }\end{array}$ & & $\begin{array}{r}\text { Low } \\
\text { vulnerability }\end{array}$ & $\begin{array}{r}\text { Medium } \\
\text { vulnerability }\end{array}$ & $\begin{array}{r}\text { High } \\
\text { vulnerability }\end{array}$ & $\begin{array}{r}\text { Very high } \\
\text { vulnerability }\end{array}$ \\
\hline \multicolumn{2}{c}{ Class values } & & $\leq 0.40$ & $0.41-0.60$ & $0.61-0.80$ & $>0.80$ \\
\cline { 5 - 7 } Inhabitants & Number & & 62415 & 82403 & 48603 & 9837 \\
& Percentage & & 30.71 & 40.54 & 23.91 & 4.84 \\
\hline \multirow{2}{*}{ Villages } & Number & & 42 & 141 & 173 & 56 \\
& Percentage & 10.19 & 34.22 & 41.99 & 13.59 \\
\hline
\end{tabular}

ratio, road accessibility, modified weight of arable land on slopes and weight of land under forestry) have been mathematically processed and standardized (values from 0 to 1 have the same significance for each factor and each place in the region). The general vulnerability index illustrates the nonlinear relationship between vulnerability and the explanatory variables, which is very important due to cumulative effect. However, being independent, this general composite index does not contain explicitly any hazard information and requires both hazard and vulnerability analysis for risk assessment and mitigation. The great advantage is the integration of the model in a Geographical Information System, which allows continuous data updating, vector and raster processing, vulnerability mapping and spatial analysis, on an adequate predefined background (level, scale and resolution).

Acknowledgements. Financial support for this study was provided by the Sectorial Operational Program Human Resources Development through the project "Development of innovative capacity and increasing of research impact by post-doctoral programs" POSDRU/89/1.5/S/49944.

The authors greatly appreciate and thank for the effort of reviewers, for their suggestions and constructive comments.

Edited by: T. Glade

Reviewed by: S. Fuchs and another anonymous referee

\section{References}

Adger, W. N.: Vulnerability, Global Environ. Chang., 16, 268-281, 2006.

Adger, W. N. and Kelly, P. M.: Social vulnerability to climate change and the architecture of entitlements, Mitigation and Adaptation Strategies for Global Change, 4, 253-266, 1999.

Alexander, D.: Natural disasters, UCL Press, London, 632 pp., 1993.

Anderson, M. and Woodrow, P.: Rising from the ashes: development strategies in times of disasters, Intermediate Technology Publications, London, 1989.

Armas I., Damian R., Sandric I., and Costache-Osaci G.: Slope vulnerability to landslides in the subcarpathian sector of Prahova valley (in Romanian), Romania of Tomorrow Foundation, 238 pp., 2003.
Birkmann, J.: Indicators and criteria for measuring vulnerability: Theoretical bases and requirements, in: Measuring vulnerability to natural hazards - Towards Disaster Resilient Societies, edited by: Birkmann, J., United Nations University Press, Tokyo, 5577, 2006a.

Birkmann, J.: Measuring Vulnerability to Promote Disaster-resilient Societies: Conceptual Frameworks and Definitions, in: Measuring Vulnerability to Natural Hazards - Towards Disaster Resilient Societies, edited by: Birkmann, J., United Nations University Press, Tokyo, 9-54, 2006b.

Blaikie, P., Cannon, T., Davis, I., and Wisner, B.: At Risk: Natural Hazards, Peoples Vulnerability, and Disasters, Routledge, London, 1994.

Böhle, H. G., Downing, T. E., and Watts, M.: Climate Change and Social Vulnerability: toward a Sociology and Geography of Food Insecurity, Global Environ. Chang., 4, 37-48, 1994.

Bohle, H. G.: Vulnerability and criticality, IHDP Update, 2, 1-7, 2001.

Brooks, N., Adger, W. N., and Kelly, P. M.: The determinants of vulnerability and adaptive capacity at the national level and the implications for adaptation, Global Environ. Chang., 15, 151163, 2005.

Cannon, T.: Vulnerability analysis and explanation of "Natural' Disasteres, in: Disasters, Development and Environment, edited by: Varley, A., Wiley, New York, 1994.

Ceobanu, C. and Grozavu, A.: Psychosocial effects of the floods. Perception and attitudes, Carpath. J. Earth Environ., 4, 25-38, 2009.

Chambers, R.: Vulnerability, coping and policy, IDS Bulletin, 20, $1-7,1989$.

Crozier, M. J. and Glade, T.: Landslide hazard and risk: issues, concepts and approach, in: Landslide hazard and risk. edited by: Crozier, M. J., Anderson, A. G., and Glade, T., Wiley, Chichester, 1-40, 2005.

Cutter, S. L.: Living with risk. The geography of technological hazards, Arnold, London-New York, 214 pp., 1993.

Cutter, S. L.: Vulnerability to environmental hazards, Prog. Hum. Geog., 20, 529-539, 1996.

Dow, K.: Exploring differences in our common future(s): the meaning of vulnerability to global environmental change, Geoforum, 23, 417-436, 1992.

Fekete, A.: Validation of a social vulnerability index in context to river-floods in Germany, Nat. Hazards Earth Syst. Sci., 9, 393403, doi:10.5194/nhess-9-393-2009, 2009.

Fuchs, S.: Susceptibility versus resilience to mountain hazards in Austria - paradigms of vulnerability revisited, Nat. Hazards 
Earth Syst. Sci., 9, 337-352, doi:10.5194/nhess-9-337-2009, 2009.

Fuchs, S., Heiss, K., and Hübl, J.: Towards an empirical vulnerability function for use in debris flow risk assessment, Nat. Hazards Earth Syst. Sci., 7, 495-506, doi:10.5194/nhess-7-4952007, 2007.

Fuchs, S., Kuhlicke, C., and Meyer, V.: Editorial for the special issue: vulnerability to natural hazards - the challenge of integration, Nat. Hazards, 58, 609-619, doi:10.1007/s11069-011-98255, 2011.

Fuchs, S., Ornetsmüller, C., and Totschnig, R.: Spatial scan statistics in vulnerability assessment: an application to mountain hazards, Nat. Hazards, online first, doi:10.1007/s11069-011-0081-5, 2012.

Füssel, H. M.: Vulnerability: A Generally Applicable Conceptual Framework for Climate Change Research, Global Environ. Chang., 17, 155-167, 2007.

Füssel, H. M. and Klein, R.: Climate change vulnerability assessments: an evolution of conceptual thinking, Climatic Change, 75, 301-329, 2006.

Haque, C. E. and Burton, I.: Adaptation options strategies for hazards and vulnerability mitigation: an international perspective, Mitigations and Adaptation Strategies for Global Changes, 10, 335-353, 2005.

Hewitt, K. (Ed.): Interpretations of Calamity, Boston, MA, and London, Allen and Unwinn, 1983.

Hufschmidt G.: A comparative analysis of several vulnerability concepts, Nat. Hazards, 58, 621-643, 2011.

Hufschmidt, G. and Glade T.: Vulnerability analysis in geomorphic risk assessment. in: Geomorphological hazards and disaster prevention, edited by: Alcantara-Ayala, I. and Goudie, A. S., Cambridge University Press, New York, 233-243, 2010.

Ionita, I.: Critical season of erosion in Barlad Plateau, in: The environmental impact of hydro-climatic and pedo-geomorphological risks in Barlad basin, edited by: Rusu, C., "Al. I. Cuza” University of Iaşi Publishing House, 160-170, 2007 (in Romanian).

Istrate, M.: Urban-rural relations in Moldavia in the contemporary period, “Al. I. Cuza” University of Iaşi Publishing House, 351 pp., 2008 (in Romanian).

Johnston, R. J., Gregory D., and Smith D.: The dictionary of human geography, Blackwell Publishers Ltd., 724 pp., 1994.

Kappes, M. S., Papathoma-Köhle, M., and Keiler M.: Assessing physical vulnerability for multi-hazards using an indicator-based methodology, Appl. Geogr., 32, 577-590, 2011.

Kasperson, J. X., Kasperson, R. E., Turner II, B. L., Schiller, A., and Hsieh, W.: Vulnerability to global environmental change, in: Social Contours of Risk. Vol. II: Risk Analysis Corporations and the Globalization of Risk, edited by: Kasperson, J. X. and Kasperson, R. E., Earthscan London, 245-285, 2005.

Kasperson, R. E., Dow, K., Golding, D., and Kasperson, J. X.: Understanding global environmental change: The contributions of risk analysis and management. Worcester, MA, Clark University, The Earth Transformed Program, 77 pp., 1990.

Kuhlicke, C.: The dynamics of vulnerability: some preliminary thoughts about the occurrence of "radical surprises" and a case study on the 2002 flood (Germany), Nat. Hazards, 55, 671-688, 2010.

Kuhlicke, Ch., Scolobig A., Tapsell S., Steinführer A., and De Marchi B.: Contextualizing social vulnerability: findings from case studies across Europe, Nat. Hazards, 58, 789-810, doi:10.1007/s11069-011-9751-6, 2011.

Liverman, D.: Vulnerability to global environmental change, in: Understanding global environmental change: the contributions of risk analysis and management, edited by: Kasperson R., Clark University, Earth Transformed Program: Worcester MA, 8-23, 1990.

Meyer, V. and Messner, F.: National flood damage evaluation methods - a review of applied methods in England, the Netherlands, the Czech Republic and Germany, UFZ-Diskussionspapiere, 21 pp., 2005.

Mileti, D. S., Darlington, J. D., Passerine, E., Forest, B. C., and Myers, M. F.: Toward an integration of natural hazards and sustainability, Environmental Professional, 17, 117-126, 1995.

Morgan, R. P. C.: Soil Erosion and Conservation, National Soil Resources Institute, Cranfield University, United Kingdom, Blackwell Publishing, 304 pp., 2005.

Moţoc, M., Munteanu, S., Băloiu, V., Stănescu, P., and Mihai, Gh.: Soil erosion and control methods (in Romanian), Ceres Publishing House Bucharest, 301 pp., 1975.

Muntele, I.: Population of Moldavia in the Last Two Centuries, Corson Publishing House, Iasi, 257 pp., 1998 (in Romanian).

Niacşu, L.: Pereschiv catchment (Tutova Hills), Study of geomorphology and pedogeography with special regard on land use, $\mathrm{PhD}$ thesis, "Al. I. Cuza” University of Iaşi, 249 pp., 2009 (in Romanian).

Niacşu, L. and Stângă, I. C.: Role of bio-pedological relations for landscape evolution in Tutova Hills, Proceedings of II-nd Int. Scientific and Practical Conference Ecology: Problems of adaptive-landscape agriculture, Ivano-Frankivsk, Ukraine, 2430, 2006 (in French).

O'Brien, K., Eriksen, S., Schjolden, A., and Lygaard, L.: What's in a word? Conflicting interpretations of vulnerability in climate change research, CICERO Working Paper, Oslo, 2004.

Papathoma-Köhle, M., Neuhäuser, B., Ratzinger, K., Wenzel, H., and Dominey-Howes, D.: Elements at risk as a framework for assessing the vulnerability of communities to landslides, Nat. Hazards Earth Syst. Sci., 7, 765-779, doi:10.5194/nhess-7-7652007, 2007.

Papathoma-Köhle, M., Kappes, M., Keiler, M., and Glade, T.: Physical vulnerability assessment for alpine hazards: state of the art and future needs, Nat. Hazards, 58, 645-680, doi:10.1007/s11069-010-9632-4, 2011.

Papathoma-Köhle, M., Keiler, M., Totschnig, R., and Glade, T.: Improvement of vulnerability curves using data from extreme events: debris flow event in South Tyrol, Nat. Hazards, doi:10.1007/s11069-012-0105-9, 2012.

Peduzzi, P., Dao, H., Herold, C., and Mouton, F.: Global Risk And Vulnerability Index Trends per Year (GRAVITY), Phase III: Drought Analysis, Technical Report, United Nations Environment Programme, Global Resource Information Database Geneva, UNEP/DEWA/GRID-Geneva, January 2003.

Peduzzi, P., Dao, H., Herold, C., and Mouton, F.: Assessing global exposure and vulnerability towards natural hazards: the Disaster Risk Index, Nat. Hazards Earth Syst. Sci., 9, 1149-1159, doi:10.5194/nhess-9-1149-2009, 2009.

Pelling, M.: The Vulnerability of Cities - Natural Disasters and Social Resilience, Earthscan Publications Ltd., London, 212 pp., 2003. 
Polsky, C., Neff, R., and Yarnal, B.: Building comparable global change vulnerability assessments: The vulnerability scoping diagram, Global Environ. Chang., 17, 472-485, doi:10.1016/j.gloenvcha.2007.01.005, 2007.

Popa, N.: Contributions to the development of forecasting models of soil and nutrient losses by erosion on agricultural slopes, with reference to Barlad Plateau, PhD thesis, Technical University „Gh. Asachi” Iaşi, 1999.

Quarantelli, E. L. (Ed.): What is a disaster?, London and New York, Routledge, 1998.

Rygel, L., O'Sullivan, D., and Yarnal, B.: A method for constructing a social vulnerability index: an application to hurricane storm surges in a developed country, Mitigations and Adaptation Strategies for Global Change, 11, 741-764, 2006.

Schröter, D., Polsky, C., and Patt, A. G.: Assessing vulnerabilities to the effects of global change: an eight step approach, Mitigation and Adaptation Strategies for Global Change, 10, 576-596, 2005.

Smith, K.: Environmental hazards. Assessing risk and reducing disaster, 4th Edn., Routledge, Taylor and Francis Group, London and New York, 306 pp., 2004.

Smith, K. and Petley, D. N.: Environmental hazards. Assessing risk and reducing disaster, 5th Edn., Routledge, Taylor and Francis Group, London and New York, 383 pp., 2008.

Sorocovschi, V.: Vulnerability as component of risk. Concept, control variable, types and assessment models, in Risks and Catastrophes, vol. VI, Books for Science Publishing House, ClujNapoca, Romania, 58-69, 2007 (in Romanian).

Stângă, I. C.: Natural risks. Terms and concepts, "Al. I.Cuza" University of Iaşi Publishing House, 109 pp., 2007 (in Romanian).

Stângă, I. C.: Tutova basin. Natural risks and territory vulnerability, PhD. thesis, "Al. I. Cuza” University of Iaşi, 242 pp., 2009 (in Romanian).

Stângă, I. C. and Rusu, C.: The concepts of vulnerability and resilience used in natural risks analysis, Buletinul Societăţii de Geografie din România, Bucureşti, 12, 129-142, 2006.

Susman, P., O'Keefe, P., and Wisner, B.: Global disasters: A Radical Interpretation, in: Interpretations of Calamity, edited by: Hewitt K., Allen and Unwin, Boston/London, 263-283, 1983.

Taubenböck, H., Post, J., Roth, A., Zosseder, K., Strunz, G., and Dech, S.: A conceptual vulnerability and risk framework as outline to identify capabilities of remote sensing, Nat. Hazards Earth Syst. Sci., 8, 409-420, doi:10.5194/nhess-8-409-2008, 2008.

Timmerman, P.: Vulnerability, Resilience and the Collapse of Society, Environmental Monograph, no. 1, Institute for Environmental Studies, University of Toronto, 1981.
Totschnig, R., Sedlacek, W., and Fuchs, S.: A quantitative vulnerability function for fluvial sediment transport, Nat. Hazards, 58, 681-703, 2011.

Tudora D.: The geographical distribution of social indices of rural population in Western Moldavia, PhD. thesis, "Al. I. Cuza" University of Iaşi, 400 pp., 2010 (in Romanian).

Turner II, B. L., Kasperson, R. E., Matsone, P. A., McCarthy, J. J., Corell, R. W., Christensen, L., Eckley, L., Kasperson, J. X., Luerse, A., Martello, M. L., Polsky, C., Pulsipher, A., and Schiller, A.: A Framework for Vulnerability Analysis in Sustainability Science, P. Natl. Acad. Sci. USA, 100, 8074-8079, 2003a.

Turner II, B. L., Matson P. A., McCarthy, J. J., Corell, R. W., Christensen, L., Eckley, N., Hovelsrud-Broda, G. K., Kasperson, J. X., Kasperson, R. E., Luers, A., Martello, M. L., Mathiesen, S., Naylor, R., Polsky, C., Pulsipher, A., Schiller, A., Selin, H., and Tyler, N.: Illustrating the coupled human-environment system for vulnerability analysis: three case studies, P. Natl. Acad. Sci. USA, 100, 8080-8085, 2003b.

UNEP: Assessing Human Vulnerability due to Environmental Change: Concepts, Issues, Methods and Case Studies, UNEP/DEWA/RS.03-5, 2002.

UN-ISDR (United Nations - International Strategy for Disaster Reduction): Living with risk, A global review of disaster reduction initiatives, United Nations report, 382 pp., 2002.

Varnes, D. J.: Landslides hazard zonation: a review of principles and practice, UNESCO, 1984.

Villa, F. and McLeod, H.: Environmental Vulnerability Indicators for Environmental Planning and Decision-Making: Guidelines and Applications, Environ. Manage., 29, 335-348, doi:10.1007/s00267-001-0030-2, 2002.

Watts, M. J. and Bohle, H. G.: The space of vulnerability: the causal structure of hunger and famine, Prog. Hum. Geog., 17, 43-67, 1993.

White, G. F. (Ed.): Natural Hazards: Local, National, Global. New York, Oxford University Press, 1974.

White, P., Pelling, M., Sen, K., Seddon, D., Russell, S., and Few, R.: Disaster Risk Reduction, A Development Concern, DFID, 2005.

Weichselgartner, J.: Disaster mitigation: the concept of vulnerability revisited, Disaster Prevention and Management, 10, 85-94, 2001.

Weichselgartner, J. and Bertens, J.: Natural disasters: acts of God, nature or society, edited by: Brebbia, C., Risk Analysis II, WIT Press, Southampton, 3-12, 2000.

Wisner, B., Blaikie, P., Cannon, T., and Davis, I.: At risks - Natural hazards, people's vulnerability and disasters, Second edition, Routledge, London, 471 pp., 2004. 